\title{
REMEMBRANZAS DE JOHN V. MURRA
}

\author{
Osvaldo Silva Galdames ${ }^{1}$
}

En octubre de 1971 se realizó el VI Congreso de Arqueología Chilena, uno de cuyos principales invitados era John Murra. Ahí escuché sus novedosos, al menos para mí, puntos de vista en los comentarios y debates originados tras cada presentación de las ponencias. No recuerdo qué opinión le mereció la mía pero supe que se refirió a ella en conversaciones con otros participantes de dicho encuentro. Lo que sí constituyó una sorpresa fue la invitación que me hiciera para conversar con él en su hotel. La hora fijada era las cuatro de la tarde. Jorge Hidalgo me advirtió que fuese puntual. Llegué media hora antes y esperé en la recepción hasta que, venciendo el nerviosismo y la timidez, a las cuatro en punto me hice anunciar. "Que suba" fue la respuesta recibida a través del recepcionista. Golpeé la puerta de su habitación. Tras unos segundos ésta fue abierta y John, saludándome con cordialidad, me invitó a pasar y sentarme mientras él hacía lo mismo en la cama para ponerse los calcetines, uno de los cuales tenía un notorio agujero en el dedo gordo, y calzarse los zapatos. Nada coincidía con lo que me había imaginado. Esperaba encontrarme con el típico profesor universitario que había conocido en otras universidades norteamericanas, con corbata, traje y zapatos y me hallaba frente a un personaje en camiseta, con el cinturón suelto y a pie descalzo. Tras la primera impresión, el hecho contribuyó a relajarme e iniciar una conversación en la que las preguntas apuntaban más a conocer mis experiencias que a averiguar mis conocimientos.

Pasados ya unos treinta minutos me cuenta que planeaba reunir en Cornell a un estudiante peruano y a otro chileno con el objetivo intercambiar opiniones y complementar informaciones en el análisis de aquellos aspectos propios de la cultura andina. Le interesaba especialmente la colaboración interdisciplinaria entre la antropología, arqueología e historia. Franklin Pease era su candidato del Perú y me invitaba a ser el chileno.

Me advirtió que llegar a Cornell no era decisión solo suya. Había que cumplir las normas de ingreso, ser aceptado por los miembros del Comité de
Admisión, para lo cual tenía que presentar mis antecedentes, llenar formularios, tener recomendaciones y postular en las mismas condiciones que los otros candidatos a ingresar al programa de Doctorado. El financiamiento de los estudios podría obtenerlo a través de una beca de la Fundación Ford, institución que estaba dispuesta a apoyar el proyecto.

Acepté y cumplí con todas las exigencias solicitadas. Durante el tiempo que duró este proceso recibí cartas muy formales de John Murra comunicándome oficialmente los pasos en que estaba mi postulación hasta ser, finalmente, admitido en el Departamento de Antropología de la Universidad de Cornell. A fines de 1972 la Fundación Ford me concedió la beca para iniciar mis estudios a partir de septiembre del año siguiente.

Llegué a Ithaca un día 20 de agosto. Obtuve alojamiento temporal en el Pensionado Universitario, donde, por fortuna, también se hallaban otros chilenos que me orientaron en los pasos a seguir para matricularme, buscar vivienda y desplazarme sobre el hermoso campus de Cornell. Días después llegué al Departamento de Antropología esperando encontrar al Dr. Murra. Preguntando por él conocí a Judy Willis, su secretaria, quien, con mucha amabilidad, me advirtió que para conversar con Murra debía inscribirme primero, advirtiéndome que no intentara hacerlo después de sus clases. Me anoté para el día y la hora que me sugirió. Así pude hablar, por segunda vez, personalmente con John. La entrevista fue muy formal. Me explicó que debía elegir un tutor y tras terminar el semestre refrendarlo junto a otros miembros que integrarían un Comité Académico. También me informó que Franklin Pease no vendría a Cornell, lamentando que su proyecto no prosperara. John aceptó ser el tutor y me matriculé en los seminarios que me recomendara, entre los cuales se encontraba uno dirigido por él mismo.

El seminario se realizaba en su casa. Éramos, según recuerdo, dos alumnos regulares: Freda Wolf y yo, más otros tres oyentes. El tema central se basaba en la lectura y comentario de la Visita que

Universidad de Chile, Santiago, Chile. osilva@uchile.cl 
Garcí Díez de San Miguel efectuara a Chucuito en 1567. No nos proporcionó más bibliografía, lo cual me resultó bastante extraño. Con el tiempo aprendería que ese era su método pedagógico: aprender a partir de las fuentes, lo que para una persona que recién comenzaba a introducirse en las investigaciones sobre el mundo andino resultaba muy difícil. Escuchar sobre ropa cumbi y ahuasca, por ejemplo, sin tener idea de sus diferencias, constituía un desafío muy grande. Freda intuyó mi desesperación y me aconsejó leer la tesis doctoral de Murra, regalándome, gentilmente, una fotocopia pues aún no se había publicado. Estuve dos días fichándola y recién entonces sentí que podía arreglármelas para proseguir con la Visita.

A fin de entender mejor su concepción del mundo andino y mejorar mis saberes sobre él, le solicité a Murra asistir al curso que impartía en pregrado, hecho que repetí cada vez que lo ofrecía durante mi permanencia en Cornell, a pesar de que John, sin negarse a aceptarme, me decía que me aburriría pues escucharía las mismas cosas y los mismos chistes. Comprobé que ello no era así, ya que cada vez presentaba nuevas interrogantes, abriendo otras perspectivas de investigación. Sin dudas John era un excelente profesor. Sus clases estaban llenas de histrionismo que entusiasmaban a los jóvenes estudiantes, favoreciendo un mayor acercamiento, en el cual se forjaban valiosos vínculos indispensables para un mayor éxito en el proceso de aprendizaje. Siempre vestido en forma impecable, y hasta elegante, repartía mapas, párrafos de fuentes y aun trozos de obras literarias como las de José María Arguedas, seguramente fotocopiados en la máquina Xerox que mantenía en su casa. Se paseaba, miraba fijamente a sus alumnos que, como encandilados, lo seguían en sus calculados desplazamientos, hasta que se detenía junto a uno de ellos. A veces, si había un asiento libre al lado, colocaba un pie sobre él, animándolo a dar su opinión o una respuesta. Entonces entendí la advertencia de Judy, pues debía terminar agotado después de los esfuerzos realizados en clases.

Perú estaba presente en la vida social. En una ocasión ofreció una fiesta en la que abundaría el pisco sour preparado con el licor traído por él directamente de Lima en una especie de garrafa de cinco litros. Me pidió que llegara temprano para ayudar en la preparación del brebaje, lo que hice junto a una estudiante peruana que John había conocido en Lima. En este ambiente informal conversamos de temas no académicos interesándose por saber sobre mi vida fuera de la Universidad. Afloraba el aspecto humano que echaba de menos en la relación maestro y alumno que habíamos mantenido hasta ese momento.

Preparé el trabajo final del seminario leyendo crónicas y fuentes primarias que fichaba prácticamente todo el tiempo en que no asistía a clases. Finalmente me decidí por un tema relacionado con el tributo en el estado inca a fin de acercarlo un poco a la información recogida por Diez de San Miguel. No me parecía que Murra lo encontraría bueno y novedoso, pero para mí significaba un progreso enorme en cuanto al conocimiento de nuevas fuentes y a uno de los aspectos económicos más sobresalientes del incario. Lo entregué el día establecido rogando al cielo que mi ignorancia sobre el imperio cusqueño no quedara al desnudo. Era diciembre y el frío arreciaba junto a la nieve acumulada por doquier. Se acercaban las fiestas navideñas y todo hacía presumir que el resultado de mi ensayo se sabría en enero. Pero John otra vez me tomó por sorpresa. Un día sábado había ido al supermercado en la mañana para aprovechar el autobús que, en la zona donde vivía, funcionaba solo hasta las dos de la tarde. Al regresar veo un gran sobre deslizado bajo la puerta. Era mi trabajo final con los comentarios y la calificación. Tenía un B+, la única que obtuve en Cornell. Sobre ella había un párrafo que decía más o menos así: "Notará usted que he puesto varias $\sqrt{ }$ en el margen para señalarle lo que me ha parecido interesante y sobre lo que se podría ahondar más. Las partes marcadas con una $\mathrm{x}$ indican lo que no me parece suficientemente justificado y le indico las lecturas que le podrían aclarar lo que sostiene. En todo caso las $\sqrt{ }$ superan a las $\mathrm{x}$, por lo que estimo que el tema podría ser mejorado". Había pasado apenas una semana de la entrega y John tuvo la gentileza, quizás previendo la importancia que tenía para mí saber su opinión, de llevarlo personalmente a mi departamento, cruzando Ithaca en el Volkswagen amarillo que arrendaba para no tener que "lidiar", como diría, con el papeleo y los gastos que implicaba ser propietario de un vehículo.

Antes de comenzar el segundo semestre volví a solicitar una entrevista a través de Judy. En la reunión me comunicó que estaría fuera de Cornell a partir del otoño de 1974 y que si yo deseaba que continuase como mi tutor estaba dispuesto a hacerlo. Confirmamos también a los otros miembros del Comité y me propuso tomar el curso que ofrecería 
sobre etnografía africana. También me sugirió que en lugar de inscribirme con otros profesores aprovechara la modalidad de "independent studies" que mantenía Cornell, para abordar temas que fuesen realmente de mi interés. Me pareció una magnífica idea pues podía abocarme a leer y escribir sobre lo que me resultaba más atrayente. Luego me habló de su archivo y el posible proyecto de venderlo a universidades, para lo cual requería de una catalogación más acorde con los cánones universales. Me invitó a su casa para mostrarme dicho archivo. Quedé impresionado de los cientos de páginas, con su correspondiente entrada, en las que estaban corcheteadas todas las citas referidas a la voz que la encabezaba. Algunas contenían más de una información, por lo que las copiaba para agregarlas a las correspondientes carillas. Así una misma ficha podía encontrarse repetida en muchas hojas con distintos encabezados. Ahí comprendí por qué las mecanografiaba sacando copias con papel carbón. La fotocopiadora obviaría, después, dicha tarea.

El valor del archivo de Murra reside en que contiene prácticamente todas las fuentes documentales andinas examinadas a lo largo de su vida, agrupadas en categorías que reflejan los intereses que guiaban sus investigaciones.

$\mathrm{Al}$ asistir a la primera reunión del curso sobre etnografía africana lo escuché hablar acerca de la tradición oral y cómo ésta podía convertirse en una fuente histórica. Jan Vansina y la influencia de los historiadores africanos que estudiaron en Francia o Inglaterra fueron el tema de esa sesión. En la siguiente ya teníamos que hablar sobre una etnografía de Ruanda con los tutsi y los hutus. Los yoruba, ibos, nuer, el reino de dahomey fueron analizados, discutiendo aspectos de sus sistemas de parentesco, generación de autoridades, economía, confrontaciones bélicas, entre otros, que después me han sido muy útiles para entender algo sobre los mapuches del siglo XVI. Sólo John podía dictar un curso como ese, a pesar de no haber estado nunca en el continente negro y de su insistencia en que no estaba muy al día en los estudios africanistas realizados durante la segunda mitad del siglo XX. Creo que fue muy importante en mi formación a pesar que mi primera reacción había sido ¿para qué voy a perder el tiempo leyendo etnografías que no me servirán de nada? Como los libros no estaban a la venta los fotocopié y aún suelo releerlos en búsqueda de respuestas a las preguntas que surgen en la documentación.
La relación social se hizo más fluida. Con cierta frecuencia me invitaba a cenar, especialmente cuando recibía en su casa amigos venidos del Perú. Me regalaba recortes de diarios rumanos con noticias de Chile, señalándome que no sería muy difícil para mí leerlos. La verdad es que terminé entendiendo casi la mitad de las informaciones.

En un momento pensé que era necesario retribuir y lo invité a mi departamento. Nos esmeramos en tener una buena comida, con pisco sour de aperitivo y vino chileno. La charla fue muy amena con sus anécdotas y cuentos sobre algunos "tíos" que había conocido. Nos contó algo de su infancia, de cómo había aprendido idiomas. Al revelarnos su fecha de nacimiento, 24 de agosto de 1916, no pude dejar de comentarle que ese mismo día, pero cuatro años antes, había nacido mi padre. No se pronunció sobre la coincidencia. Luego nos reveló que los "gringos" nunca pudieron pronunciar bien su apellido paterno, que hasta hoy desconozco, razón por la cual lo cambió por el de Murra.

Unos dos o tres meses después, una tarde me encontré con él en el Departamento de Antropología. Como no me había inscrito para una cita, lo saludé y lo acompañé hasta la puerta de su oficina. Me despedí y había dado ya unos cuantos pasos hacia el Laboratorio de Arqueología, cuando escucho que me llama. "Quisiera invitarlo a cenar", me dijo. Encantado, le respondí, ¿Cuándo? "El próximo viernes en su casa", me contestó medio sonriendo. "Yo llevo la comida", agregó. "Ustedes tengan el postre. Estaré a las 7 de la tarde". Justo a la hora diviso por la ventana el Volkswagen amarillo y a John bajando de él con una gran fuente en sus manos. Era una deliciosa pierna de cordero que me pareció haber visto en el freezer del sótano de su casa, donde conservaba todos los comestibles adquiridos cuando viajaba a la ciudad de New York. Estaba de muy buen ánimo y la charla se prolongó hasta casi la medianoche. En esas ocasiones nunca tocamos temas relacionados con el estudio o las investigaciones. Ayudaba a ello el que tuviéramos amigos chilenos comunes, sobre cuyas actividades podíamos comentar por horas. También se hacían referencias a historiadores y arqueólogos ya fallecidos. Expresaba gran respeto por Ricardo Latcham pues consideraba que era el único que realmente había leído las crónicas del Perú.

Se acercaba el fin del año académico 1973-1974 cuando me propuso que leyéramos las crónicas de las guerras civiles del Perú durante el verano. A pesar 
del calor y la humedad le gustaba pasar en Ithaca los meses estivales porque no había tantos alumnos (entre las dos universidades existentes allí, éstos casi igualaban en cantidad a la población local). Nos reuníamos, durante dos horas, en su casa cada miércoles en la mañana. Sentados en una especie de corredor que daba a la calle comentábamos lo que habíamos leído y él se explayaba en los hechos, personajes y actuación de españoles e indígenas, con datos que no aparecían en el cronista analizados. El sabía mucho más que yo de la historia política colonial temprana del Perú, por lo cual mi aporte era casi nulo. Sin embargo, continuamos con las sesiones hasta completar las seis semanas proyectadas.

Un día, cuando ya estábamos por finalizar la sesión, tocó la puerta un señor que resultó ser un vendedor de seguros. John, casi como jugando sin que él se diera cuenta, respondía y preguntaba alargando una conversación sin sentido. Lo miraba y casi como que sonreía al contestar. Cuando por fin le dijo amablemente que lo pensaría pues ya poseía un seguro, el vendedor se despidió. Apenas cerró la puerta se lanzó a reír: “¿se fijó en él? ¿Vio lo mal que le quedaba el peluquín a ese pobre hombre? Además el color tan poco natural", comentó. Yo no me había dado cuenta que llevaba una peluca pues el corte parecía natural. Así descubrí otra faceta de su personalidad que no volví a observar y que, quizás, pocos conozcan.

Después de lo que yo estimaba un fracaso en la lectura de las guerras civiles del Perú, me comenzó a hablar de la Visita de los valles de Sonqo en los yunkas de coca de La Paz, de su proyecto de publicarla (aparecería recién en 1992) y que le había solicitado colaboración a Rolando Mellafe. Luego me pregunta si he leído manuscritos del siglo XVII. Le respondo que no y que mis conocimientos de paleografía se reducían a un curso al que asistí en la Academia de Historia del Valle durante mi estadía en Cali. Su presidente era paleógrafo, enseñando con documentos esencialmente del siglo XVIII. Me miró y casi como una casualidad me dijo que tenía un microfilm de la Visita y como yo ya había escrito un trabajo sobre la coca, quizás me interesaría para comprobar si podía leerla. El trabajo aludido me parecía malo y mi argumento era que la coca también podría haber servido para estimular el poder sexual masculino. Lo presenté en coautoría con un estudiante uruguayo de química, quien se había inscrito en un curso sobre ecología andina, solicitándome que redactáramos juntos el trabajo final pues él, aunque no tenía idea sobre el mundo andino, sí sabía acerca de las propiedades químicas del alcaloide. Acepté porque estaba como oyente y no dañaría mis calificaciones. ¿Cómo llegó a manos de Murra? No lo sé, pero sí que lo leyó pues, al pasar, me comentó que en Ecuador había unas figuras de cerámica, con la bola de coca entre los dientes y la mejilla, en evidentes actitudes sexuales.

Murra consiguió una lectora de microfilm y me comprometí a intentar. Pasé unas dos horas mirando la primera foja y a pesar de los esfuerzos no conseguí leer ni una palabra. Busqué lo más evidente como si o no, sin encontrarlos. Cuando me aprestaba a enrollar el microfilm apareció John preguntando “¿cómo le fue?” Le conté mi fracaso. Encendió la luz de la lectora y me fue mostrando cómo había que empezar dibujando los trozos en el papel y que pronto podría separar las palabras. Así lo hice durante una semana y aunque logré leer casi tres cuartas de cada línea de las cinco primeras páginas. Me pareció que el esfuerzo y dedicación en tiempo para tener finalmente muchos espacios en blanco, superaban mis disponibilidades para ello. Después ya en Chile pude leer algunos papeles del siglo XVII, con diferentes formas de escritura, en las que quedaron 4 ó 5 espacios sin comprender, los que fueron resueltos con ayuda de Sonia Pinto.

A mediados de 1975 mi Comité estimó que ya podía presentarme al examen de admisión a la tesis. No recuerdo bien si fueron cuatro o cinco días en que había que redactar tres ensayos basados en preguntas hechas por los integrantes de él. Las recibía en la mañana y debía entregarlas, a máquina y con copias, al día siguiente, momento en que entregaban las otras preguntas. La tarea finalizaba, según recuerdo, el viernes y el siguiente miércoles, en forma muy solemne, se efectuaba la defensa oral. Cada profesor efectuaba sus comentarios a mis respuestas, los que debía contestar con todos los argumentos apropiados para justificar mis planteamientos. Luego los otros miembros del Comité procedían a realizar sus correspondientes interrogatorios. Un verdadero martirio pues había que citar autores, obras o documentos que avalaran lo sostenido. Afortunadamente y aunque nunca llegué a dominar el inglés, fui aprobado unánimemente. Era el final de la estadía como estudiante. Sólo quedaba presentar la tesis, lo que no era un gran obstáculo pues antes de la defensa ya cada examinador había hecho sus sugerencias metodológicas o teóricas. 
Sobre el tema no se dudaba que el tesista sabía más que los miembros del Comité.

Finalizado el examen, John, como me había anunciado el último día de entrega de los ensayos, me invitó a almorzar a un elegante restaurante en State Street, calle principal de Ithaca. "Ahora podemos volver a comer juntos. Nadie podrá acusarnos de sobornos", me dijo con su típica sonrisa mientras abría la carta. No recuerdo lo que ordenamos pues todavía estaba consumido por los nervios. Disfrutamos de lo que John seguramente me sugirió pedir, acompañado de un vino blanco del valle de Napa en California. Me felicitó por el examen y comentó algunos de mis ensayos en forma muy positiva. Hablamos de la tesis y le expresé que me interesaba ahondar en el tema de la presencia inca en Chile, para lo cual planeaba integrar informaciones arqueológicas e históricas.

Debí regresar a Chile a fines de ese año por imperativo de las autoridades universitarias que se negaron a ampliar el permiso para permanecer en Cornell. John estaba en Princeton o en Perú. Freda Wolf, amable y generosa amiga, en un nevoso día de diciembre nos llevó al aeropuerto, no sin dificultades por la cubierta de nieve que tapaba las pistas y dificultaban la visión. Así terminó mi contacto con Ithaca y Cornell. Esporádicamente intercambiamos cartas con algunos profesores y amigos que proseguían sus estudios. Murra continuaba siendo mi director de tesis y me había impuesto dos obligaciones: que los estudios arqueológicos proyectados en nuestras conversaciones fuesen avalados por fuentes coloniales tempranas, en lo posible inéditas y relatos de cronistas.

Mi siguiente encuentro personal con John se produjo en Santiago dos o tres años después. Le expliqué las dificultades que tenía para dedicarle más tiempo a la tesis, la poca información encontrada en las fuentes impresas y en los cronistas y sólo contaba con dos o tres documentos inéditos, cuya ubicación se la debía a una de las notas en la obra de Ricardo Latcham. "Recuerde que a pesar de no existir en Cornell un plazo para entregar la tesis, yo me acerco al momento de jubilar y, como el resto del Comité, no soy un recurso renovable", fue su única observación.

Cenamos en mi casa y el tema no volvió a tocarse. Al viajar a Ithaca yo tenía una pequeña cava de vinos que mi padre se encargó de mantener casi exacta. Se la mostré a John quien eligió una botella para la comida. Tenía unos doce años de guarda y
John disfrutó del sabor y bouquet del vino. Meses después recibí una carta suya en la que incluía un recorte de una revista, conteniendo sugerencias sobre la forma de almacenar vinos en espacios pequeños, estableciendo dónde se hallaban, sus cepas y años de cosecha, utilizando un programa computacional. No recuerdo mi respuesta pero sí el asombro que me causó su remembranza de la cava.

El año 1979 fue invitado a participar en la Escuela de Verano que organizaba la Universidad de Chile. Quedamos en que lo recogería en el aeropuerto. El avión aterrizó cerca de las 10 de la mañana y John venía agotado con un viaje que para él ya se hacía demasiado largo debido a su imposibilidad de dormir durante el vuelo. Cuando íbamos rumbo al departamento donde se hospedaría me cuenta que olvidó el traje y los pantalones que traía para las clases en el auto arrendado a fin de trasladarse de Ithaca hacia Nueva York. "¿Cree posible comprar algo pues las clases comienzan el lunes?", inquirió. Felizmente era sábado y los malls ya habían brotado en Santiago. Lo llevé al Apumanque donde Johnson's tenía una pequeña pero bien surtida tienda. Solicitó ver trajes pero no le gustó ninguno de los colores. Pasamos a las chaquetas. Escogió seis o siete y se las fue probando una por una frente a un gran espejo. Se daba vueltas para verse de frente y de espalda. Hacía gestos como si estuviese dirigiéndose a la audiencia. Se sacaba una y volvía a ponerse otra. Tras casi una hora desechó algunas y dejó tres para la selección final. Repitió la primera escena hasta que se decidió por una, y se hizo el examen final, gesticulando ademanes y posiciones con ella. Realmente le quedaba y se le veía bien. Su elección fue adecuada ya que las hombreras y mangas parecían haber sido hechas por un sastre a la medida. Luego los pantalones. Eligió esta vez uno por recomendación del vendedor, quien empleó como excusa verificar la talla. La cintura ajustaba en forma perfecta. El problema era el largo. En día sábado y pasado el mediodía la tienda no podía hacer las bastillas. Ante mi insistencia el dependiente llamó por teléfono a un "sastre" amigo quien aceptó realizar el arreglo siempre que se lo lleváramos antes de almuerzo y lo retiramos después de las 6 de la tarde. John tenía la costumbre de guardar el dinero que le sobraba cuando sabía que volvería al país. Lo que traía no alcanzaba para cancelar el monto. Lo hicimos con mi Visa. Partimos al sastre, le midieron el largo, lo que también implicó pruebas hasta lograr que le quedaran justo donde el deseaba. Habían pasado 
más de tres horas y media. Quedé de regresar donde el pretendido sastre a la hora fijada y nos dirigimos al departamento. Le pregunté si deseaba comer algo y me dijo que no pues estaba muy cansado, estado que no demostró durante las pruebas y repruebas, y que solo quería dormir.

Abrí el departamento, lo inspeccionamos para verificar que todo estaba correcto. El refrigerador, sin embargo, se hallaba vacío. John prefirió quedarse y salir más tarde a aprovisionarse en el supermercado que divisamos en las cercanías del edificio. Aceptó cenar en mi casa y quedé de recogerlo después de retirar sus pantalones.

El domingo prefirió quedarse para preparar su clase inicial del lunes. El lunes llegamos a la Escuela de Derecho. Había una gran cantidad de asistentes. Sacó unas hojas amarillas con apuntes hechos en colores azules, negro y rojo, las que iba lanzando al suelo cuando pasaba a la siguiente ¡Todo un espectáculo! El auditorio aumentó en las reuniones posteriores y las preguntas se incrementaron. Algunas eran tan básicas que temí que recibiesen una ironía de parte de John, pero él las respondió todas con la misma seriedad. El mundo andino, la complementariedad ecológica y las diferentes metodologías empleadas para darle vida a las informaciones documentales, matizadas con anécdotas, encantaron a un público que, seguramente, escuchaba por primera vez muchos de los conceptos vertidos en las exposiciones de ese profesor impecablemente vestido, al que despidieron con un estruendoso aplauso.

Hablamos de Cerro Verde, el pequeño centro ceremonial inca que encontré junto con George Serracino en la confluencia de los ríos Caspana y Salado. Lo describí y le comenté que me pareció tener un ushnu. Comentamos sobre ello, me proporcionó referencias y recomendó cómo verificar si realmente era un centro ceremonial. Le expliqué que no había encontrado fuentes documentales y sólo sonrió. Después le mostraría diapositivas, planos y mapas y le planteé la posibilidad de que se tratase de un tinku. "Es probable", respondió, alentándome a que continuara con las investigaciones pues ya tenía uno de los requisitos para la tesis.

Nuestros encuentros posteriores estuvieron casi acotados a sus viajes a Chile pues siempre pasaba por Santiago. Recuerdo que una vez venía de Buenos Aires y traía sobrepeso. Me pidió que le guardara la ropa que no requería llevar consigo para ajustarse a los kilos del equipaje permitido.
Todavía conservo parte de ella ya que no quiso, en los viajes siguientes, llevársela a menos que fuese una molestia para mí mantenerla. A pesar de almacenarla en bolsas plásticas no me percaté que las polillas dejaron lleno de agujeros el chal de lana de vicuña y alpaca que le habían regalado sus alumnos en Buenos Aires.

En La Paz supe de sus penurias al tener que cumplir un contrato por el cual no recibía remuneración hasta entonces. Me presentó a una joven a quien le había aconsejado venir a nuestro programa de Magíster en Etnohistoria, en el cual él había sido profesor visitante por un corto período, a fin de que le describiera las características y modalidades de estudio. La niña no contaba con autorización de sus padres, pero Murra pensaba que los podría convencer ya que Santiago le parecía un lugar más tranquilo que Lima. Le interesaba que se formara académicamente pues consideraba que era inteligente y tenía los vínculos para desarrollar una buena tarea etnográfica e histórica en Bolivia. Lamentablemente su idea no se concretó.

Comimos frugalmente en su casa. Preparó una sopa a la que había puesto variedad de vegetales y papas con cáscara. Alabó el tubérculo repitiendo que se le debería levantar una estatua.

Durante el Congreso Internacional de Etnohistoria organizado en Lima por la Pontificia Universidad Católica del Perú fue la última vez que se refirió, muy al pasar, a mi tesis. Me había mandado recados para asegurarme que aceptaría lo que yo tenía y esperaba que lo hiciera pronto. Pero no me atreví a entregarle algo que sigo pensando requería encontrar algún documento.

Como Profesor Emérito de Cornell en ciertos semestres le invitaban a dictar un curso Introductorio a la Antropología. Fiel a su método les hacía leer una o dos etnografías a los novatos estudiantes. Al releer Los Argonautas del Pacífico Occidental, obra clásica de Malinowski, creyó encontrar, según me afirmó, una cierta analogía entre el kula y el tráfico del mullu en los Andes, pues las conchas constituían objetos preciosos y rituales. Se entusiasmaba contando cómo podía llegar a demostrarlo. Me adelantaba lo que después publicaría, en 1995, como " ¿Did Tribute and Markets Prevail in the Andes before the European Invasion".

Para John el mundo andino y sus áreas de influencia eran los focos a los cuales prestaba interés y entusiasmo, constituyendo el tema fundamental en el intercambio de ideas y la formulación de 
sugerencias. Atacama parecía ser su límite en Chile. Rara vez me preguntó algo sobre los mapuches, explayándose, en cambio, en la descripción de sus propias pesquisas de tal modo que la charla casi se convertía en una exposición. Así continuaba traspasando conocimientos. Largas horas las dedicó a contarme sobre el doctor Manuel Barros de San Millán y el expediente judicial del cual iba extrayendo datos, en los que aparecían informaciones acerca de sus intenciones de proteger los derechos otorgados a los "señores naturales" que habían servido a los españoles durante la conquista, su cercanía con los esclavos africanos, las acusaciones que estuvieron a punto de mandarlo a la hoguera y la forma en que se liberó de ellas, alternando los hechos con comentarios sobre la personalidad del "doctorcito", como llamaba al Licenciado. Cuando expresaba su opinión personal sobre alguna de sus actuaciones, éstas eran de tal naturaleza que uno esperaba seguir oyéndolo. Cada vez que tocaba el tema había algo nuevo en el relato, por lo que las repeticiones no cansaban. Parte de lo que le escuché fue presentado en el IV Congreso Internacional de Etnohistoria de Lima y publicado en sus actas con el título de "El Doctor Barros de San Millán. Defensor de los 'señores naturales' de los Andes" (1998).

Si mal no recuerdo la última visita de John a Santiago fue el año 2000. Almorzamos y me extrañó que sólo ordenara mariscos y pescado. Debió notarlo pues me dijo: "Este es mi último viaje a Santiago, no volveré a probar al natural el producto de su mar. En Ithaca a veces se encuentran congelados y el sabor no es el mismo". Me contó de su accidente y de la larga convalecencia en una clínica. Reclamó que demoraran en darlo de alta y que le hicieran escribir sobre aspectos de su vida. No entendí bien de qué se trataba. Se veía algo cansado, pero con buen apetito. Demostraba desear proseguir con sus investigaciones pero ya no se daba el tiempo para comunicar las fuentes examinadas ni las hipótesis que le generaban. A las cuatro tenía agendada otra reunión. Al salir del restaurante caminamos lentamente hacia el auto. Le abrí la puerta y antes de subirse me miró diciendo: "sólo Dios sabrá dónde nos volveremos a ver". Lo dejé en el lugar que me indicó. Le ayudé a bajarse y nos dimos un fuerte apretón de manos. Fue la despedida de un hombre que me enseñó más a través de sus relatos y sugerencias hechas durante las gratas charlas, fuera de los ámbitos académicos, que en las aulas.

Al comenzar estas líneas vi algunas fotografías. Observé el cambio experimentado en su rostro debido al paso de los años. De ellas quedó grabada en mi mente su figura en Ithaca porque allí adquirí, al modo de Murra, las herramientas básicas para desempeñarme en el futuro. 
